\title{
Role of quantitative diffusion-weighted imaging in differentiation between red and infiltrated marrow in pediatric patients with hematologic malignancy
}

\author{
Yosra Abdelzaher Ibrahim ${ }^{1 *}$ (D) Momena Essam Elsadawy ${ }^{1}$ and Tamer El Naggar ${ }^{2}$
}

\begin{abstract}
Background: To evaluate the role of DWI with ADC value measurement in the differentiation between bone marrow infiltration and normal red marrow in pediatric patients with hematologic malignancies

Results: Significant results were obtained between ADC values of normal red and infiltrated marrow $(p<0.005)$. $A D C$ values were significantly lower in infiltrative marrow lesions. The cutoff $A D C$ value for benign and malignant lesions was $0.612 \times 10^{-3} \mathrm{~mm}^{2} / \mathrm{s}$.

Conclusion: DWI with ADC value has an additive role in differentiation between infiltrative lesions from foci of red marrow in patients with hematological malignancies.

Keywords: Hematologic malignancy, Leukemia, Lymphoma, Diffusion-weighted imaging (DWI), Apparent diffusion coefficient (ADC), Marrow infiltration, Red marrow
\end{abstract}

\section{Background}

Hematologic malignancies can affect the pediatric and the adult age groups. The commonest are leukemia and lymphoma [1]. These account for $50 \%$ of childhood malignancies and originate from hassling cell lines with overlapping imaging manifestations; however, the clinical picture, radiological findings, and treatment plans differ considerably according to the specific subtype [2].

Leukemia is the commonest malignancy in pediatrics. Acute lymphoblastic leukemia (ALL) is the commonest diagnosed type [3].

Lymphomas are broadly classified into: Hodgkin lymphoma (HL) and non-Hodgkin lymphoma (NHL). The latter is approximately 8 times more common [4].

Hematological malignancies are mainly diagnosed by complete blood picture $(\mathrm{CBC})$ and bone marrow $(\mathrm{BM})$ biopsy. However, magnetic resonance imaging (MRI) can give worthy information in the detection of the bone

\footnotetext{
* Correspondence: yosra_ibrahim@med.asu.edu.eg; yosra_zaher@yahoo.com ${ }^{1}$ Radiology Department, Faculty of Medicine, Ain Shams University, Abbaseya Square, Cairo 11566, Egypt

Full list of author information is available at the end of the article
}

marrow and soft tissue infiltration [4]. It has the advantage of assessing the whole marrow cavity compared to the limited sample of the marrow obtained from one location at biopsy/aspiration. However, MRI assessment of BM in infancy and early childhood remains challenging [5].

Diffusion-weighted imaging (DWI) is a recent addition to the conventional MRI sequences used to assess the bone marrow. It gives both quantitative and qualitative functional data concerning the water motions at a cellular level [6].

On DWI, malignant BM lesions appear hyper-intense, while benign lesions appear hypo-intense or iso-intense. In addition, benign lesions demonstrate increased apparent diffusion coefficient (ADC) value as compared to malignant lesions [4]. These data can be utilized to differentiate leukemic infiltrates from foci of red marrow especially post therapy regenerated red marrow, which usually appear as multifocal small focal areas of low signal intensity on T1-weighted images (T1WI) and high signal intensity on T2- or STIR (short TI inversion recovery) images within the fatty converted marrow, hence causing diagnostic dilemma. 

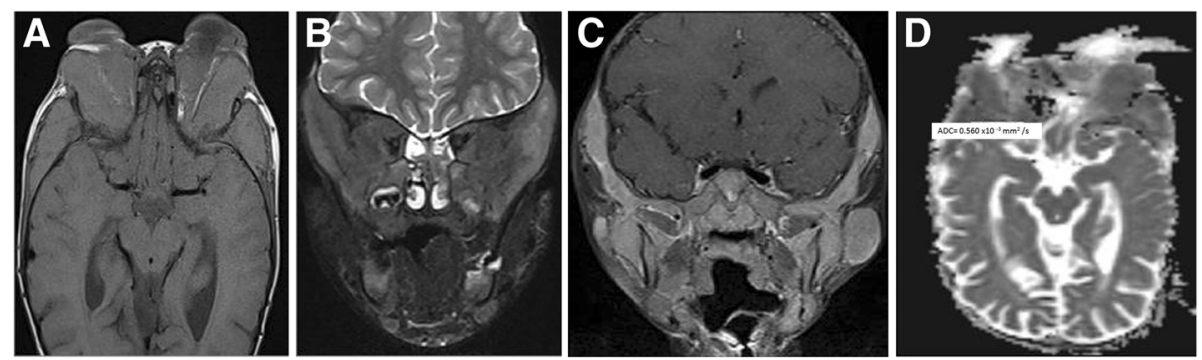

Fig. 1 A 6-year-old boy presented with facial swelling, laboratory investigation, and bone marrow biopsy revealed acute myeloid leukemia. Head MRI showed bilateral rather symmetrical abnormal marrow signal and expansion of both temporal bones. These show low signal on T1WI (a) and high signal on STIR (b) with appreciable post contrast enhancement (c) and diffusion restriction with low ADC value (d) that is calculated to be $0.560 \times 10^{-3} \mathrm{~mm}^{2} / \mathrm{s}$. The picture is of diffuse marrow infiltration of both temporal bones

The objective of this study is to assess the role of diffusion-weighted imaging with ADC value calculation in the discrimination between bone marrow infiltration and normal red marrow in pediatric patients with hematologic malignancies.

\section{Patients and methods}

The study was approved by the local institutional review board and was conducted over a period of 1 year.

\section{Patients}

The study involved 63 patients with known hematological malignancy (leukemia or lymphoma) and bone marrow infiltration. Forty-eight (76.2\%) of them had leukemia (42 had ALL and 6 had AML). Fifteen (23.8\%) patients had lymphoma. All were diagnosed by bone marrow biopsy. They were 26 (41\%) females and 37 (59\%) males. Their age ranged from 1.5 years to 16 years, with a mean age of 9 years. All cases were referred to the MRI unit for head, spine, or extremity imaging to delineate the extent of marrow infiltration that was detected on plain X-ray. Sedation was used in uncooperative young patients below 7 years of age.

\section{Exclusion criteria}

- Patients age $>18$ years.

- Patients who have contraindications to MRI (e.g., cochlear implant).

\section{Control subjects}

An age- and sex-matched control group was selected from our PACS station. They were pediatric patients referred for brain MRI. Indications for MRI in these children were convulsion, headache or dizziness. They were a total of 20 controls: 12 males and 8 females, with a mean age of 6.5 years (range: 19 months to 14 years). The exclusion criteria for control subjects were:

- History of preterm delivery or low birth weight.

- Musculoskeletal, metabolic, or systemic diseases.

- Children with a history of any medications which may affect the bone marrow.

\section{MR imaging sequences, processing, and interpretation} The MRI examinations were performed on a superconducting $1.5 \mathrm{~T}$ unit (Siemens, MAGNETOM ${ }^{\circ}$ scanner).

\section{Sequences}

All subjects were scanned using standard protocol with a dedicated coil. The pulse sequences included:

- T1-weighted (T1W) images (fast spin-echo sequence): repetition time $(\mathrm{TR})=595 \mathrm{~ms}$, echo time $(\mathrm{TE})=11$ ms, number of excitations (NEX) 2, flip angle 90, matrix $150 \times 236$ with a field of view (FOV) as small as possible, slice thickness $4-5 \mathrm{~mm}$, and gap $0.5 \mathrm{~mm}$.

- T2-weighted (T2W) images (fast spin-echo sequence) $: \mathrm{TR}=3670 \mathrm{~ms}, \mathrm{TE}=92 \mathrm{~ms}, \mathrm{NEX}=3$, flip
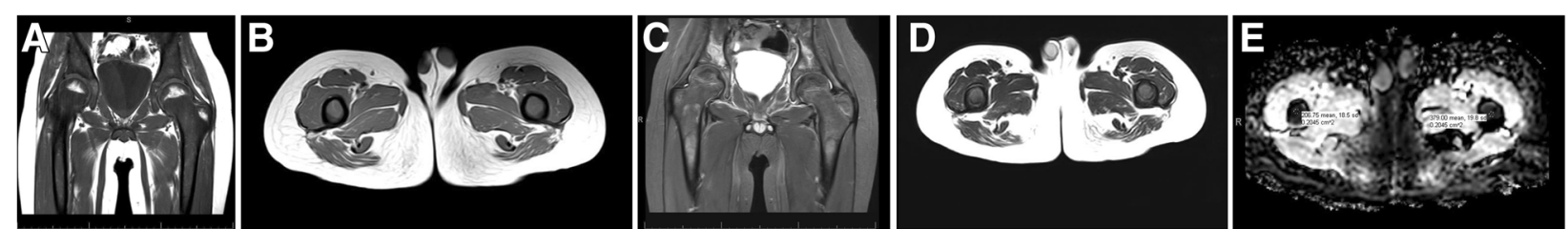

Fig. 2 A 12-year-old male with known ALL. MRI of the pelvis showed diffuse marrow infiltration of the pelvic bones and upper femora. The lesion appeared as diffuse abnormal marrow signal eliciting low $\mathrm{T} 1(\mathbf{a}, \mathbf{b})$, intermediate T2 and STIR signal (c and $\mathbf{d}$, respectively) with low signal on ADC map (e). ADC values were $0.206 \times 10^{-3} \mathrm{~mm}^{2} / \mathrm{s}$ and $0.379 \times 10^{-3} \mathrm{~mm}^{2} / \mathrm{s}$ in the right and left femur, respectively 

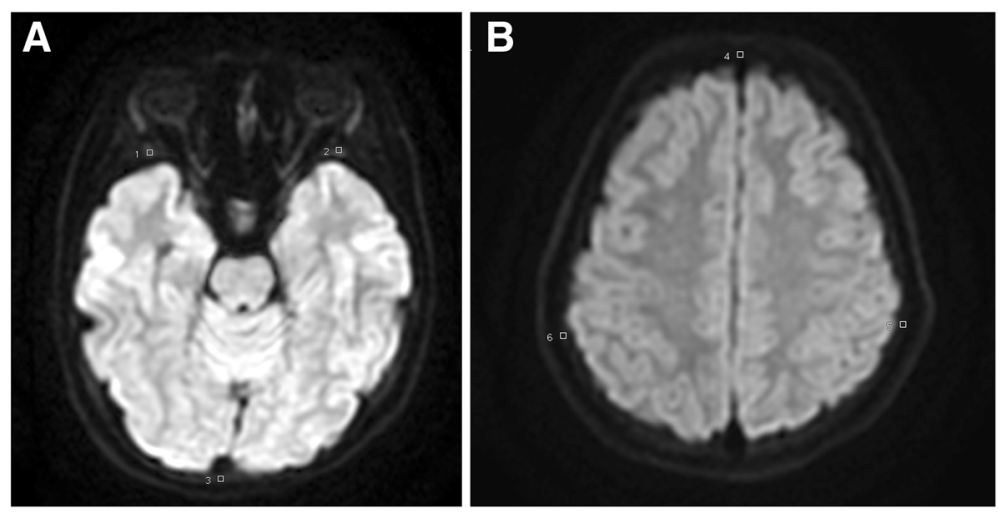

Fig. 3 DWI images of a 12-year-old control child showing the location of the different regions of interest used for ADC calculation. a ROls placed in the right and left greater wing of sphenoid bone (ROI 1 and 2) and the occipital bone ROI 3). b ROI placed in the frontal bone (ROI 4) and both parietal bones (ROI 5 and 6).

angle 90,matrix $150 \times 236$ with a FOV as small as possible, slice thickness $4-5 \mathrm{~mm}$, and gap $0.5 \mathrm{~mm}$.

- STIR: TR = $3670 \mathrm{~ms}$, TE = $92 \mathrm{~ms}, \mathrm{NEX}=3$, flip angle 110 , matrix $150 \times 236$ with a FOV as small as possible, slice thickness $4-5 \mathrm{~mm}$, and gap $0.5 \mathrm{~mm}$.

- Post contrast fat-suppressed T1WI in at least two planes.

- DWI: Fat-suppressed single-shot echo-planar DW imaging was acquired in the axial/sagittal plane with three directional diffusion gradients by using $b$ values 0,400 , and $800 \mathrm{~s} / \mathrm{mm}^{2}$ in the spine and extremity imaging while using $b$ values of 0 and $1000 \mathrm{~s} / \mathrm{mm}^{2}$ in the head imaging. Parameters were as follows: $\mathrm{TR}=6090 \mathrm{~ms}$, $\mathrm{TE}=83 \mathrm{~ms}, \mathrm{NEX}=3$, matrix $150 \times 236$, slice thickness $4-5 \mathrm{~mm}$, and gap $0.5 \mathrm{~mm}$.

\section{Image evaluation}

-A marrow lesion was considered to be infiltrative lesion if it shows:

1) Increase bone girth (Fig. 1)

2) Abnormal signal (low T1WI and high T2WI and STIR signal) concerning marrow conversion pattern of the affected bone (Figs. 1 and 2).

3) Heterogeneous contrast enhancement (Fig. 1c).

\section{ADC calculation}

Patients: The mean ADC value of the detected marrow lesion was calculated by drawing an ROI (region of interest) over the whole lesion. The ROIs might be drawn directly on the ADC map or copied from those drawn on the DW-MR images onto the map (Figs. 1d and 2e).

Controls: ROIs were placed on 6 points as follows: The frontal bone, the right and left parietal bones, the right and left greater wings of sphenoid, and the occipital bone (Fig. 3). Then, the mean ADC value was calculated for the six measurements.

\section{Statistical analysis}

Mann-Whitney $U$ test was used to compare ADC values of normal red marrow versus infiltrative marrow lesions. A $p$ value of less than 0.05 was considered statistically significant.

Receiver operating characteristic (ROC) curve analyses were performed to assess the diagnostic performance of the ADC values and to determine suitable ADC cutoff points to separate red marrow from infiltrated marrow. A $p$ value of less than 0.05 was considered statistically significant.

All analyses were performed using IBM SPSS statistical software (V. 24.0, IBM Corp., USA, 2016).

\section{Results}

The ADC of marrow infiltrative lesions was ranging from 0.36 to $0.529 \times 10^{-3} \mathrm{~mm}^{2} / \mathrm{s}$ with a mean value of $0.502 \times 10^{-3} \mathrm{~mm}^{2} / \mathrm{s}$.

In normal control subjects, the mean ADC values obtained at the different skull areas are summarized in Table 1.

The normal marrow ADC value ranged from 0.902 to $1.34 \times 10^{-3} \mathrm{~mm}^{2} / \mathrm{s}$ with a mean value of $1.2 \times 10^{-3} \mathrm{~mm}^{2} / \mathrm{s}$.

Table 2 demonstrates the ADC mean and range among patients versus controls.

We found no significant correlation between ADC value and patient age $(p=0.161)$

Table 1 The mean ADC value calculated in different skull regions

\begin{tabular}{ll}
\hline Skull region & Mean ADC $\left(\times 10^{-3} \mathrm{~mm}^{2} / \mathrm{s}\right)$ \\
\hline The frontal bone & 1.2 \\
The right parietal bone & 1.4 \\
The left parietal bone & 1.6 \\
The right greater wing of the sphenoid & 1.03 \\
The left greater wing of the sphenoid & 0.96 \\
The occipital bone & 1.035 \\
\hline
\end{tabular}


Table 2 The ADC value calculated in the patients versus controls

\begin{tabular}{lll}
\hline Patients ADC value (range and mean) & Controls ADC value (range and mean) & $p$ value \\
\hline 0.36 to $0.529 \times 10^{-3} \mathrm{~mm}^{2} / \mathrm{s}$, mean $=0.502 \times 10^{-3} \mathrm{~mm}^{2} / \mathrm{s}$ & $0.902-1.34-10^{-3} \mathrm{~mm}^{2} / \mathrm{s}$, mean $=1.2-10^{-3} \mathrm{~mm}^{2} / \mathrm{s}$ & $(p=0.005)$ \\
\hline
\end{tabular}

ADC values were significantly lower in infiltrative marrow lesions compared to normal red marrow $(p=0.005)$ which is considered highly significant. The best ADC cutoff level derived from the ROC analysis (Fig. 4) to differentiate marrow infiltration from red marrow was $0.612 \times 10^{-} 3 \mathrm{~mm}^{2} / \mathrm{s}$, giving $100 \%$ sensitivity and $94.4 \%$ specificity with the positive and negative predictive value of $97 \%$ and $100 \%$, respectively.

\section{Discussion}

Since the relaxation rates and MR signal patterns of highly cellular hematopoietic marrow and highly cellular infiltrated marrow are similar, the discrimination between reconverted highly cellular normal red marrow and recurrent malignancy after chemotherapy is not possible with conventional MR techniques. In addition, an infiltration with less than $20 \%$ neoplastic cells cannot be distinguished from normal marrow with standard MR pulse sequences [7].

During the last years, the primary target for DWI was processes involving the bone marrow. The application of DWI in BM is currently an established technique that offers a unique contrast which helps in the detection of bone-marrow pathologies and differentiation of benign from malignant bone-marrow lesions [8].

Most experience has been gained for differentiating pathologic from benign compression fractures of the vertebrae, which can be reliably done with quantitative diffusion measurements [9].

Malignant tumors tend to have low ADC values due to increased cellularity.
In our study, patients with bone marrow infiltration showed ADC values ranged from 0.36 to $0.529 \times$ $10^{-3} \mathrm{~mm}^{2} / \mathrm{s}$. These results agreed with the study of Dietrich et al. [10] who found untreated patients to have ADC values of $0.48 \pm 0.13 \times 10^{-3} \mathrm{~mm}^{2} / \mathrm{s}$. However, our results disagreed with that of Coa et al. [11] whose patients showed ADC values of $0.81 \pm 0.43 \times$ $10^{-3} \mathrm{~mm}^{2} / \mathrm{s}$. This could be attributed to the different age group as they studied adult patients.

In this study, subjects with normal red marrow showed ADC values ranged from 0.902 to $1.34 \times 10^{-3}$ $\mathrm{mm}^{2} / \mathrm{s}$ which agreed with Dietrich et al. [10] and Coa et al. [11] where control patients showed ADC values of $1.29 \pm 0.591 \times 10^{-3}$ and $1.5 \pm 0.48 \times 10^{-3} \mathrm{~mm}^{2} / \mathrm{s}$, respectively.

Concerning the relation between growing age and $A D C$ value, we found no correlation between $A D C$ value of normal marrow and growing age which agreed with Herrmann et al. [12] who reached the same conclusion in 2012. Whereas Manupolos and Koutoulidis [13] have stated that there is a correlation between growing age and ADC value of the normal marrow. Such discrepancy could be attributed to the fact that they have included adult subjects in their study unlike Herrmann et al. whose studied age group was similar to ours.

According to our result, the best ADC cutoff value for discrimination between infiltrated and normal marrow was $0.594 \times 10^{-3} \mathrm{~mm}^{2} / \mathrm{s}$, giving $100 \%$ sensitivity and 94.4\% specificity. This disagrees with Padhani et al. [14] who stated that the best cutoff value for differentiating neoplastic marrow infiltration from normal marrow is $0.77 \times 10^{-3} \mathrm{~mm} 2 / \mathrm{s}$ with a sensitivity of $85 \%$ and a specificity of $90 \%$. This difference could be attributed to the

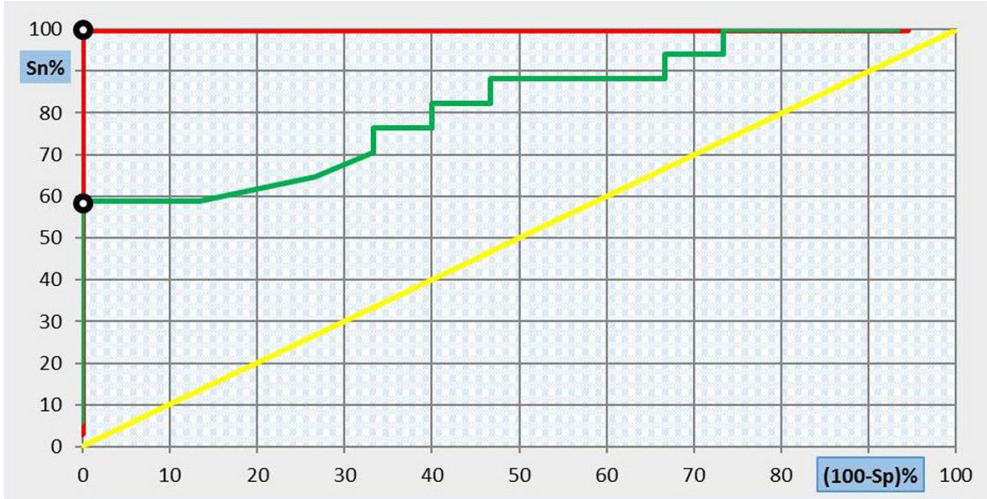

Fig. 4 ROC curve analysis showing the diagnostic performance of ADC for discriminating red from infiltrated marrow 
fact that Padhani et al. have included adult cases with hematological malignancy i.e., multiple myeloma.

\section{Conclusion}

Conventional MRI sequences including T1 and T2WI are not usually reliable to discriminate red marrow from infiltrated marrow. DWI with ADC value has an additive role in differentiation between infiltrative lesions from red marrow reconversion in patients with hematological malignancies.

\section{Abbreviations}

ADC: Apparent diffusion coefficient; ALL: Acute lymphoblastic leukemia; BM: Bone marrow; CBC: Complete blood picture; DWI: Diffusion-weighted imaging; HL: Hodgkin lymphoma; MRI: Magnetic resonance imaging; NHL: Non-Hodgkin lymphoma; STIR: Short TI inversion recovery; T1WI: T1weighted imaging

\section{Acknowledgements}

Not applicable

\section{Author's contributions}

$\mathrm{Yl}$ participated in the sequence alignment and drafted the manuscript. ME participated in the sequence alignment and helped to draft the manuscript. TN participated in the design of the study and performed the statistical analysis. All authors read and approved the final manuscript.

\section{Funding}

Not applicable

\section{Availability of data and materials}

The datasets used and/or analyzed during the current study are available from the corresponding author on reasonable request.

Ethics approval and consent to participate

The study was approved by the local institutional review board.

\section{Consent for publication}

Not applicable

\section{Competing interests}

The authors declare that they have no competing interests.

\section{Author details}

${ }^{1}$ Radiology Department, Faculty of Medicine, Ain Shams University, Abbaseya Square, Cairo 11566, Egypt. ${ }^{2}$ General Organization for Teaching Hospitals and Institutes, Cairo, Egypt.

Received: 22 June 2019 Accepted: 22 July 2019

Published online: 06 September 2019

\section{References}

1. Keraliya AR, Krajewski KM, Giardino AA, Tirumani SH, Shinagare AB, Ramaiya $\mathrm{NH}$, Jagannathan JP (2015) Imaging of nervous system involvement in hematologic malignancies: what radiologists need to know. American Journal of Roentgenology. 205:604-617

2. AverillGunselAcikgoz W, Miller RE, Kandula VR, Epelman M (2013) Update on pediatric leukemia and lymphoma imaging. Department of Medical Imaging, Nemours Children's Hospital, Orlando, pp 9-17

3. Smith MA, Gloeckler Ries LA, Gurney JG, Ross JA (1999) Leukemia SEER pediatric monograph. In: Gloeckler Ries LA, Smith MA, Gurney JG et al (eds) Cancer incidence among children and adolescents: United States SEER program 1975-1995. National Cancer Institute, Bethesda, pp 17-34.4

4. Vassilakopoulos TP, Pissakas GJ (2014) Introduction to lymphomas. In: Gouliamos AD, Andreou JA, Kosmidis PA (eds) Imaging in clinical oncology, 1st edn. Springer, pp 235-238
5. Bracken J, Nandurkar D, Radhakrishnan K et al (2013) Normal pediatric bone marrow: magnetic resonance imaging appearances from birth to 5 years. J Med Imaging Radiat Oncol 57:283-291

6. Khoo MY, Tyler PA, Saifuddin A, Padhani AR (2011) Diffusion-weighted imaging (DWI) in musculoskeletal MRI: a critical review. Skeletal Radiol. 40: 665-668

7. Lecouvet FE, Vande Berg BC, Michaux L, Malghem J, Maldague BE, Jamart J, Ferrant A, Michaux JL (1998) Stage III multiple myeloma: clinical and prognostic value of spinal bone marrow MR imaging. Radiology 209:653-660

8. Balzarini L, Sicilia A, Ceglia E, Tesoro JD, Trecate G, Musumeci R (1996) Magnetic resonance in primary bone tumors: a review of 10 years of activities. Radiol Med 91:344-347

9. Herneth $\mathrm{AM}$ et al (2005) Diffusion weighted imaging of bone marrow pathologies. European Journal of Radiology. 55(1):74-83

10. Dietrich O, Geith T, Reiser MF, Baur-Melnyk A (2017) Diffusion imaging of the vertebral bone marrow. NMR in Biomedicine 30:3

11. Cao W, Liang C, Gen Y et al (2016) Role of diffusion-weighted imaging for detecting bone marrow infiltration in skull in acute lymphoblastic leukemia. Diagnostic and Interventional Radiology. 22(6):580-586

12. Herrmann J, Krstin N, Schoennagel BP (2012) Age-related distribution of vertebral bone-marrow diffusivity. Eur J Radiol. 81:4046-4049

13. Manupolos LA (2015) MRI of the normal bone marrow. In: Moulopoulos LA Koutoulidis $\vee$ (eds) Bone marrow MRI: a pattern-based approach, 1st edn. Springer, pp 1-172

14. Padhani AR, Van Ree K, Collins DJ et al (2013) Assessing the relation between bone marrow signal intensity and apparent diffusion coefficient in diffusion-weighted MRI. American Journal of Roentgenology 200(1):163-170

\section{Publisher's Note}

Springer Nature remains neutral with regard to jurisdictional claims in published maps and institutional affiliations.

\section{Submit your manuscript to a SpringerOpen ${ }^{\circ}$ journal and benefit from:}

- Convenient online submission

- Rigorous peer review

- Open access: articles freely available online

- High visibility within the field

- Retaining the copyright to your article

Submit your next manuscript at $>$ springeropen.com 